\title{
Investigation of sticky-rice lime mortar of the Horse Stopped Wall in Jiange
}

\author{
Yan-Bing Luo ${ }^{*}$ and Yu-Jie Zhang
}

\begin{abstract}
Background: The Horse Stopped Wall, built by sticky-rice lime in Jiange County Sichuan Province, is still conserved well after thousands of years of erosions by environmental conditions such as humidity variations, pollutions, air, etc. In this paper, mortar samples from the Horse Stopped Wall were characterized via X-ray diffraction, thermogravimetry, Fourier transform infrared spectroscopy, iodine-starch analysis and scanning electron microscopy in order to better understand its properties.

Result: The results showed that the inorganic ingredients were mainly calcite and a small amount of lime in the mortar. There was still a small quantity of sticky-rice after such a long period of time. The reason that the lime was not transformed into calcite completely might be ascribed to it being wrapped by the sticky-rice in the mortar.

Conclusions: Sticky-rice lime was traditionally used widely as a good natural architectural material in ancient China. The samples from Jiange County were characterized and the results showed that most of the lime had been transformed to calcite and the rest of which might be wrapped by sticky-rice. The reason the mortar could resist damages from its natural environment over such a long period of time is the interaction of the sticky-rice mortar and calcium hydroxide and their resulting micro structure.
\end{abstract}

Keywords: Sticky-rice lime mortar, TG-FTIR, XRD

\section{Background}

The Horse Stopped Wall, located in Liangshan village and built about three thousand years ago, is a section of Cuiyun corridor of Jianmenshudao, one of the most beautiful and the oldest road in the northwest of China. The characteristics of the wall were "three ancients", namely the ancient road, the ancient tree and the ancient traffic facilities. In the ancient China, the Horse Stopped Walls, just as the name implied, were a kind of military constructions to set to protect horses from falling off the cliff, similar to today's super highway. They were usually more than one meter in height and 0.8 meter in width, and their length depended on the danger of the road. There were two types of the Horse Stopped Walls: soil walls which were constructed by pebbles and muds in the middle, and stone walls which were built by bluestones and mortar where the sticky-rice lime acted as adhesive and the lime was painted on the wall surface to draw people's attention.

\footnotetext{
* Correspondence: luoybs@126.com

School of History \& Culture, Center for Archaeological Science, Sichuan University, 29 Wangjiang Road, Chengdu 610064, China
}

This wall in Jiange County was one meter in height and located at the road bends and only on one side of the road. During the Ming Zhengde Dynasty (A.D. 1506-1521), the governor Libi organized craftsmen to rebuild the ancient road. The wall still retains its original appearance and the sticky-rice lime remains integrated after thousands of years of erosion by its environment.

It was recorded that sticky-rice lime mortar (SLM) was widely used in the ancient Chinese buildings such as tombs, the constructions of cities and water conservancy projects [1-4]. The method of preparation SLM was to cook the sticky-rice, boil to a paste, and then mix with sand and lime. Due to SLM's high strength, good toughness and superior seepage-proof quality, it can also be called "Chinese concrete". Archaeological studies showed that the SLM was used widely in the Northern and Southern Dynasties until modern times such as Kaiping Diaolou in the early 1930s, and it faded out of the historical stage with the development of the western concrete $[5,6]$. However, SLM holds an important status and value in Chinese architectural history. Domestic and foreign scholars, especially conservators, have paid much
() Chemistry Central

C 2013 Luo and Zhang; licensee Chemistry Central Ltd. This is an Open Access article distributed under the terms of the Creative Commons Attribution License (http://creativecommons.org/licenses/by/2.0), which permits unrestricted use,

distribution, and reproduction in any medium, provided the original work is properly cited. 


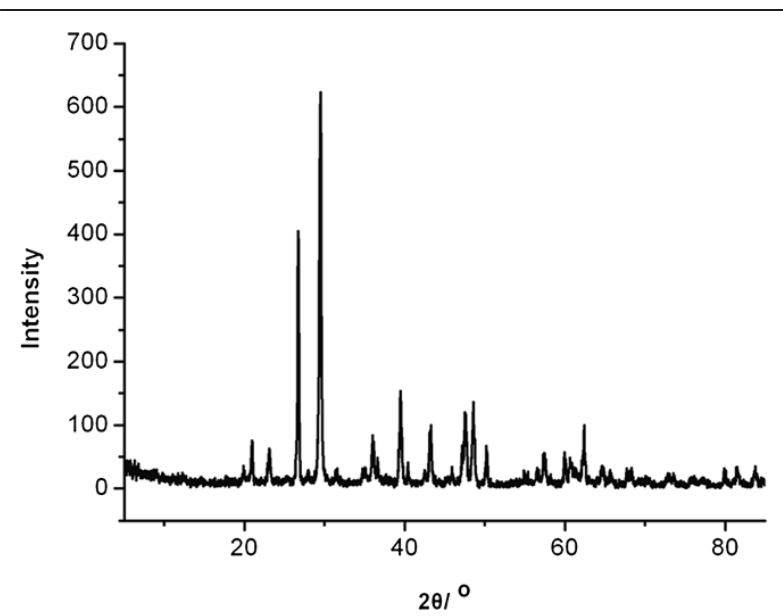

Figure 1 XRD patterns of SLM. X-ray diffraction patterns of SLM were evaluated by a DX-1000 diffractometer.

special attention to it due to its excellent performance such as surface hardness, antibacterial activities, and environmentally-friendly characteristics. Scholars from National Cheng Kung University (NCKU) and Zhejiang University have conducted research works with SLM from the city walls constructed in the Song and Ming Dynasties. It was reported that sticky- rice played a crucial role in the consolidation properties of lime mortars [7-9].

In this work, sticky-rice lime obtained from the Horse Stopped Wall in Jiange County was analyzed by Fourier transform infrared spectroscopy (FTIR), X-ray diffraction (XRD), thermogravimetry - Fourier transform infrared spectroscopy (TG-FTIR), scanning electron microscopy
(SEM) for the first time. The aim of this work is to have a full understanding of the status quo of the materials used in the Horse Stopped Wall.

\section{Results and discussion}

The XRD pattern of samples, as illustrated in Figure 1, shows that calcite is the main mineral (signals at $2 \theta=23.1,29.5,39.5,47.6,48.6^{\circ}$ ). The signals at $2 \theta=20.8$, $26.7,39.4^{\circ}$ correspond to quartz which came from soil.

The FTIR spectra of the bare sticky-rice and SLM are presented in Figure 2. The bands at 875 , and $710 \mathrm{~cm}^{-1}$ were ascribed to the deformation vibration of $\mathrm{CO}_{3}^{2-}$ and $\mathrm{O}-\mathrm{C}-\mathrm{O}$ of calcite. The infrared absorption bands at $1421 \mathrm{~cm}^{-1}$ of calcite are shifted to $1448 \mathrm{~cm}^{-1}$. The reason that the asymmetric stretching vibration of $v(\mathrm{O}-\mathrm{C})$ of $\mathrm{CaCO}_{3}$ was shifted to higher wavenumber could be that the organic materials in mortars caused the crystal deformation of $\mathrm{CaCO}_{3}$. The bands in the $1000-1150 \mathrm{~cm}^{-1}$ spectral region were ascribed to the stretching vibration of $\mathrm{C}-\mathrm{OH}$ of polysaccharide which was the degradation product of sticky-rice.

In order to confirm whether the lime had transformed into calcite completely, the $\mathrm{pH}$ of the SLM was calculated. The $\mathrm{pH}$ of the SLM was 11.73 meaning that the $\mathrm{Ca}(\mathrm{OH})_{2}$ was not transformed into $\mathrm{CaCO}_{3}$ completely. This result could indicate that the unreacted $\mathrm{Ca}(\mathrm{OH})_{2}$ could be wrapped by organic materials or else it should have been transformed into calcite in the air after such a long period of time. At the same time, the residual $\mathrm{Ca}$ $(\mathrm{OH})_{2}$ maintained an alkaline environment which restrained the growth of the bacteria and conserved the SLM for such a long period of time.

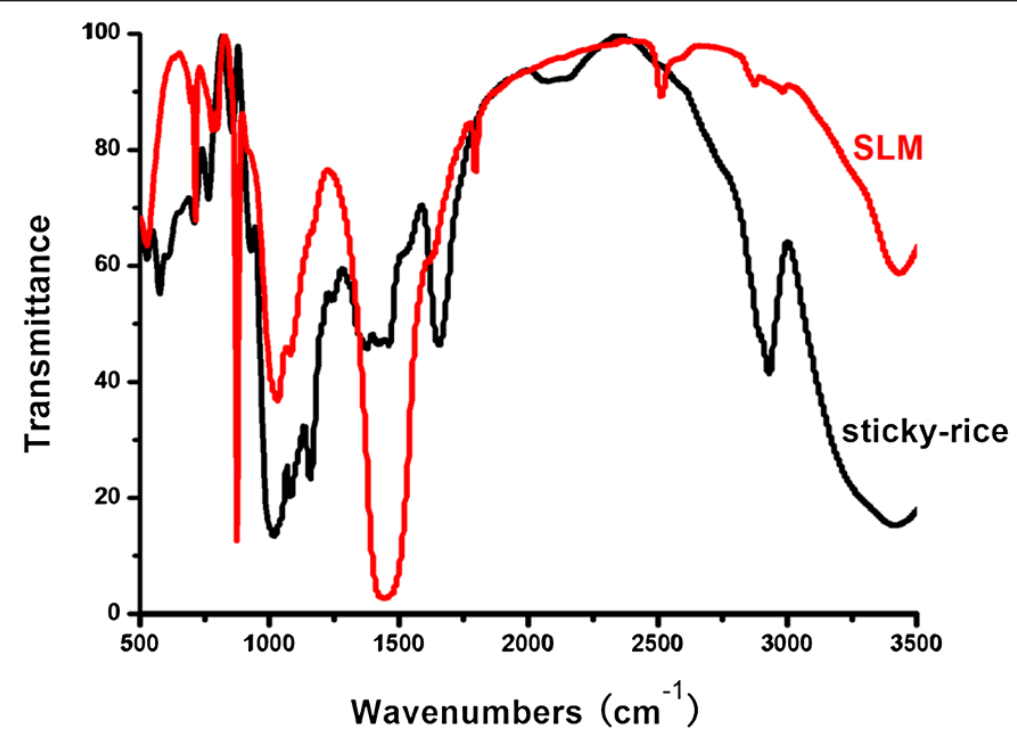

Figure 2 FTIR spectra for sticky-rice and SLM. The measurements were carried out with a Nicolet 6700 FTIR instrument. The spectra were recorded from 400 to $4000 \mathrm{~cm}^{-1}$ with a spectral resolution of $4 \mathrm{~cm}^{-1}$ and 32 scans. 


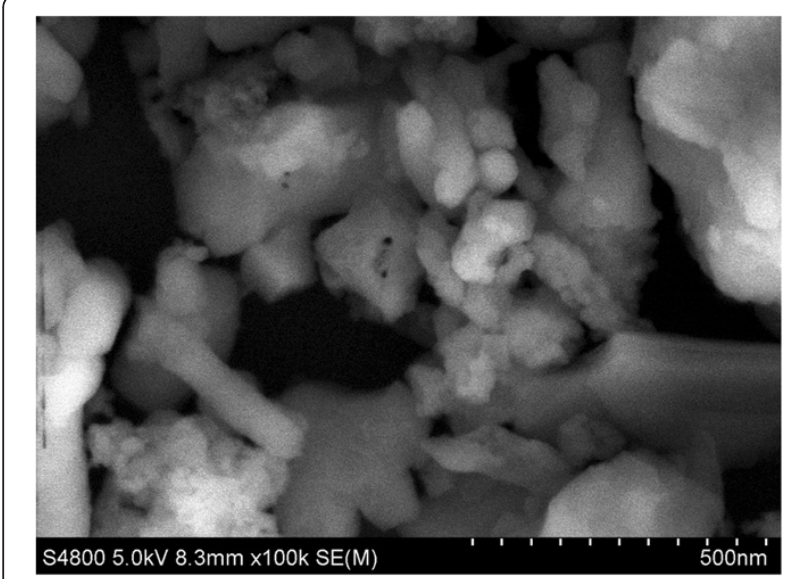

Figure 3 SEM image of SLM. SEM images were recorded with a Philips FEI INSPECT F instrument operated at $10 \mathrm{kV}$ with a very thin gold layer deposited by sputtering under vacuum. Scale bars $=500 \mathrm{~nm}$.

The $\mathrm{I}_{2}$-starch reaction has proven to be a powerful tool to show whether amylopectin, the main component of sticky-rice, existed or not. It is a very sensitive chemical reaction even though the amount of the iodine was only $4 \times 10^{-5} \mathrm{~mol} / \mathrm{l}$. The $\mathrm{I}_{2}$-starch experiment yielded a purple solution when the SLM was reacted with the iodine. The result of the $\mathrm{I}_{2}$-starch reaction supported the hypothesis that there was still sticky-rice in the samples after such a long period of time under the burial condition. More details are discussed in the following sections.

Scanning electron microscopy (SEM) was employed to explore the microstructure of the SLM. Figure 3 shows the SEM micrographs of SLM. It can be seen from Figure 3 that the particles are small, and of irregular shape, which further suggests that the lime and/or calcite might be wrapped by sticky-rice.

We were not able to find out the exact initial ratio of each component in SLM, but TG could be a very useful instrument to investigate the composition of the mortar. Figure 4 shows the results of derivative thermogravimetry (DTG) as a function of temperature for the pure stickyrice and SLM. It was found that the maximal decomposition temperature for the pure sticky-rice was at $257^{\circ} \mathrm{C}$. It can be seen clearly that the decomposition of SLM involved three stages, and the maximal decomposition temperatures were found at $249^{\circ} \mathrm{C}, 395^{\circ} \mathrm{C}$ and $708^{\circ} \mathrm{C}$ respectively. The three stages seemed to correspond to the degradation of the organic component, the decomposition of $\mathrm{Ca}(\mathrm{OH})_{2}$, and the decomposition of the $\mathrm{CaCO}_{3}$, respectively. The maximal decomposition temperature for organic component in SLM was slightly lower than that of the pure sticky-rice, which could be attributed to the effects of the inorganic components. The organic component and $\mathrm{CaCO}_{3}$ constituted $2.7 \%$ and $78 \%$ of SLM mass according to the weight loss data, respectively.

In order to further confirm the decomposition patterns, the FTIR spectra corresponding to the three decomposition stages were obtained by TG-FTIR. Figure 5 shows the change in absorbance for bands at $2359 \mathrm{~cm}^{-1}$ of the FTIR spectra for the gas generated when heating the SLM. The band at $2359 \mathrm{~cm}^{-1}$ indicates the presence of $\mathrm{CO}_{2}$ gas streams released from the samples. When samples were heated during the first stage, the slowly change in

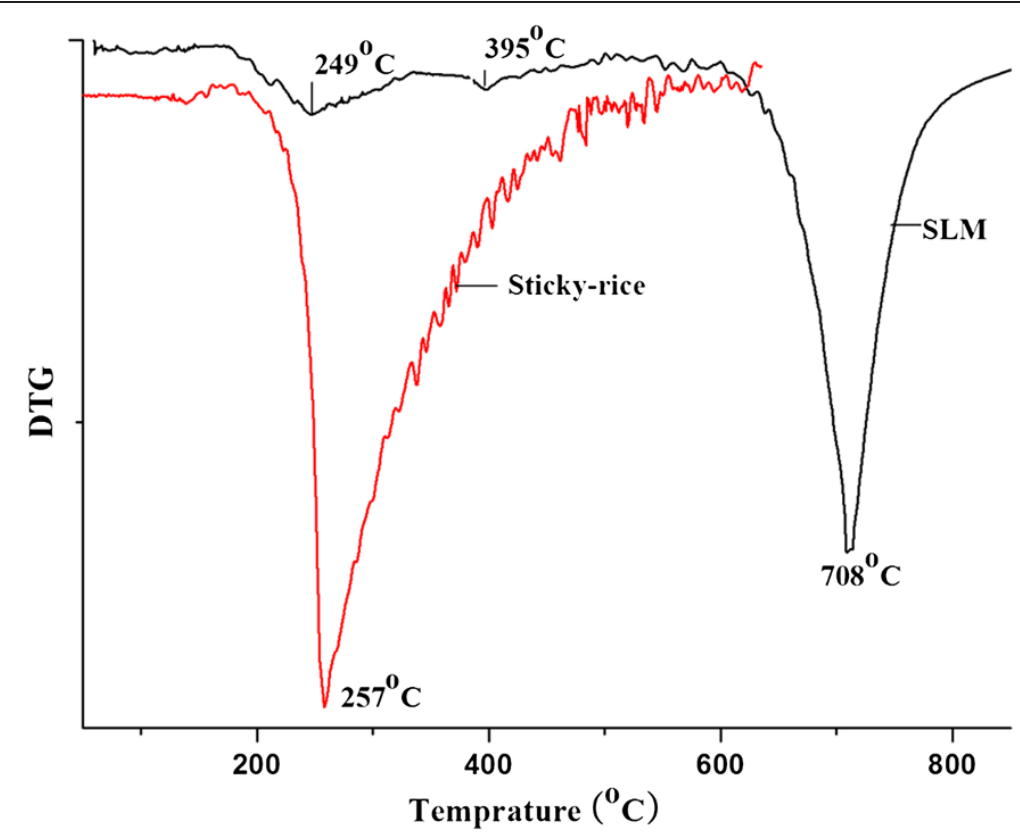

Figure 4 DTG curve of SLM. The derivative thermogravimetry was recorded using a TG 209 F1 (NETZSCH Instrument). 


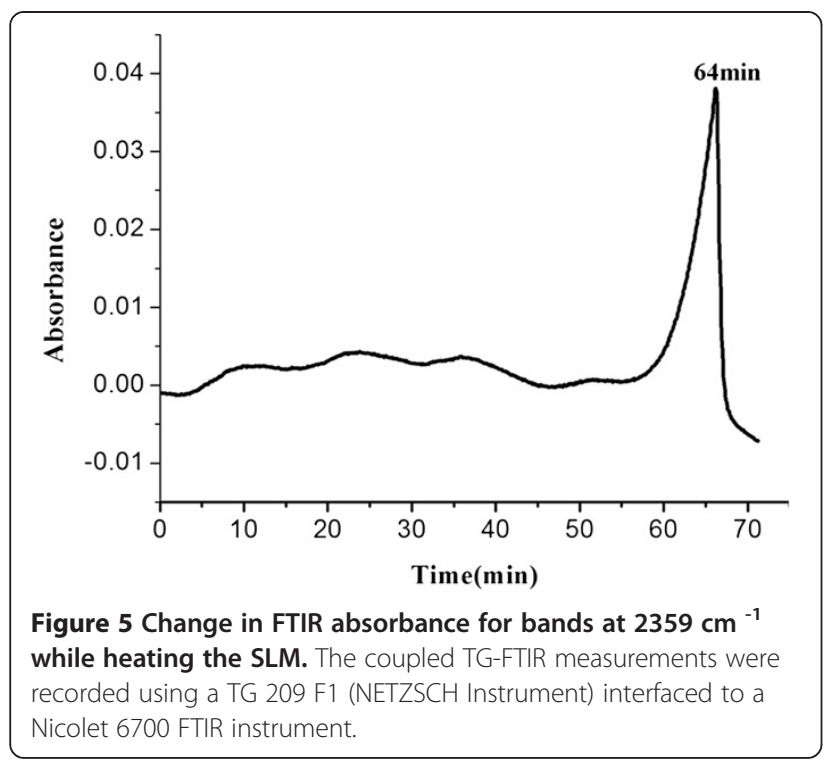

characteristics of the band at $2359 \mathrm{~cm}^{-1}$ suggests the released substance containing $\mathrm{CO}_{2}$ gas, matching the decomposition of sticky-rice and its degradation products. When the SLM was further heated, at $43 \mathrm{~min}, \mathrm{CO}_{2}$ $\left(2359 \mathrm{~cm}^{-1}\right)$ was disappeared, matching the second stage of the decomposition of $\mathrm{Ca}(\mathrm{OH})_{2}$. The intensity of absorption band at $2359 \mathrm{~cm}^{-1}$ increased quickly after the $\mathrm{CO}_{2}$ signal started to increase at $53 \mathrm{~min}$, and the maximum absorbance was at $64 \mathrm{~min}$. The results of the bands at $2359 \mathrm{~cm}^{-1}$ obtained by TG-FTIR supported the evidence that the SLM comprised organic, $\mathrm{Ca}(\mathrm{OH})_{2}$ and a large amount of $\mathrm{CaCO}_{3}$.

\section{Conclusions}

Mortar samples from the Horse Stopped Wall in Jiange County Sichuan Province were characterized for the first time. The results showed that the inorganic ingredients of the samples were mainly calcite and a small amount of lime, and that there was still a small quantity of sticky-rice. The lime had not been transformed into calcite completely according to the results of TG-FTIR and $\mathrm{pH}$ tests. The residual $\mathrm{Ca}(\mathrm{OH})_{2}$ maintained an alkaline environment which prevented the growth of bacteria and conserved the SLM. The reason that the mortar could resist damages from the natural environment for such a long period of time is the interaction of the sticky-rice mortar and calcium hydroxide and their resulting micro structure. We will further investigate the samples of the mortar to understand the properties of the ancient Chinese SLM in the future.

\section{Methods}

\section{Samples}

Sticky-rice lime mortar was sampled from the Horse Stopped Wall ruins in Jiange. The sampling site was showed in Figure 6.

\section{Characterization}

XRD was recorded on a DX-1000 diffractometer equipped with a graphite monochromator and $\mathrm{Cu} \mathrm{K} \alpha(\lambda=1.5418 \AA)$ radiation. The generator was operated at $40 \mathrm{kV}$ and $25 \mathrm{~mA}$. The samples were scanned at diffraction angle from $2^{\circ}$ to $70^{\circ}$ at the scanning rate of $0.06^{\circ} / \mathrm{sec}$.

SEM images were recorded with a Hitachi fields S4800 instrument operated at $20 \mathrm{kV}$.

The FTIR analysis was performed on samples using a Thermo Nicolet 6700 spectrometer. The spectra were recorded from 400 to $4000 \mathrm{~cm}^{-1}$ with a spectral resolution of $4 \mathrm{~cm}^{-1}$ and 32 scans.

The coupled TG-FTIR measurements were carried out with a TG 209 F1 (NETZSCH Instrument) interfaced to a Nicolet 6700 FTIR instrument. The heating from room temperature to $900^{\circ} \mathrm{C}$ was conducted at a rate of $10^{\circ} \mathrm{C} / \mathrm{min}$ in the TG $209 \mathrm{~F} 1$, under ultrahigh-purified nitrogen at a flow rate of $20 \mathrm{~mL} / \mathrm{min}$. The outlet gas cell was maintained at $235^{\circ} \mathrm{C}$ and placed inside the FTIR spectrometer. FTIR scans were made in the frequency range of $4000-400 \mathrm{~cm}^{-1}$ at approximately $25 \mathrm{~s}$ intervals to obtain time (or temperature) resolved FTIR spectra.
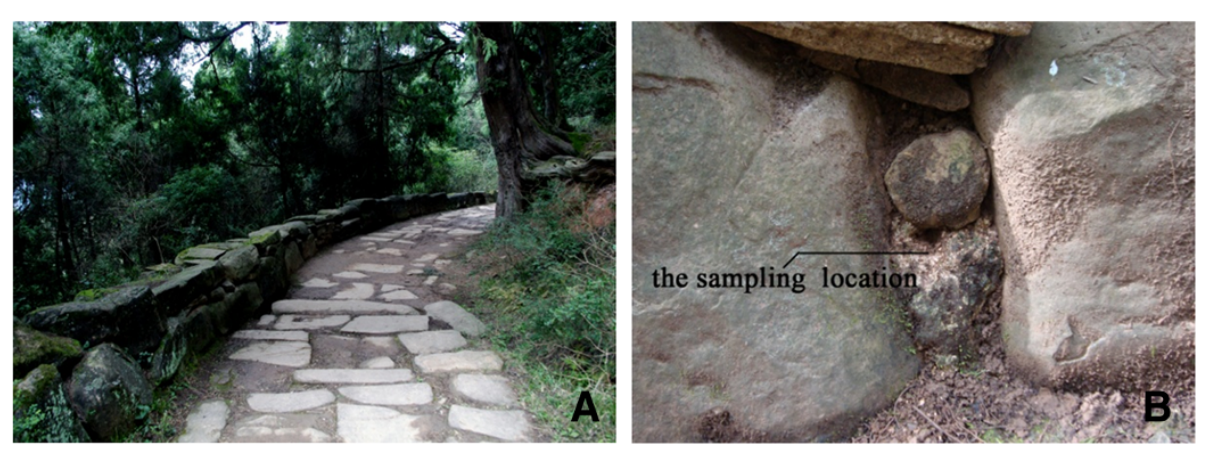

Figure 6 Photographs of the Horse Stopped Wall in Jiange County and the sampling location. (A) the Horse Stopped Wall (B) the sampling location. 


\section{Competing interests}

All authors declare that they have no competing interests.

\section{Authors' contributions}

Y-BL conceived the study, designed the experiments, drafted the manuscript; Y-JZ performed the experiments. Both the authors read and approved the final manuscript.

\section{Acknowledgments}

This work was supported financially by the Younger Fund of the Ministry of Education (10XJCZH005) and the advanced interdisciplinary innovation research project of Sichuan University (skqy201216).

Received: 15 May 2013 Accepted: 13 August 2013

Published: 15 August 2013

\section{References}

1. Qing-Zhou W: Experience and its reference of the flood control in ancient China History. City Plann Rev 2002, 26(5):76-84.

2. Ma J: Princess tomb discovered in East China Jiaotong University. Relics from South 2003, 3:115-117.

3. Wang X-S: Primary exploration of protection and application technology in Chinese ancient city walls. Tradit Chinese Architecture Gardens 2004, 1:220-222.

4. Huan-Yang Y, Dan C: Protection and development of tourism resources of the Qiantang river in Ming and Qing Dynasties. Zhejiang Sci Technol Water Resour 2004, 4:9-10.

5. Henan Provincial Cultural Bureau work team of cultural relics: Deng County color brick tomb. Peiking: Cultural Relics Publishing Company; 1958.

6. Xiu-Ying S, Pei-Llin L, Abby L: Type, value and heritage management Model of Diao tower in Kai Ping. J Hunan Univ Arts Sci (Social Science Edition) 2006, 4:95-99.

7. Chen J-L: Ratio and strength relationships of historic mortar materials, Master degree thesis. Tainan: National Cheng Kung University; 2004.

8. Yang $\mathrm{f}$, Zhang $\mathrm{B}$ j: Exploratory research on the scientific nature and application of traditional sticky rice mortar. Palace Mus J 2008, 139(5):109-114. 159.

9. Yu-Yao Z, Bing-Jian Z, Xiao-Lin L: Study on characteristics and consolidation mechanism of historical mortar materials. Sci Conserv Archaeology 2008, 20(2):1-8.

doi:10.1186/2050-7445-1-26

Cite this article as: Luo and Zhang: Investigation of sticky-rice lime

mortar of the Horse Stopped Wall in Jiange. Heritage Science 2013 1:26.

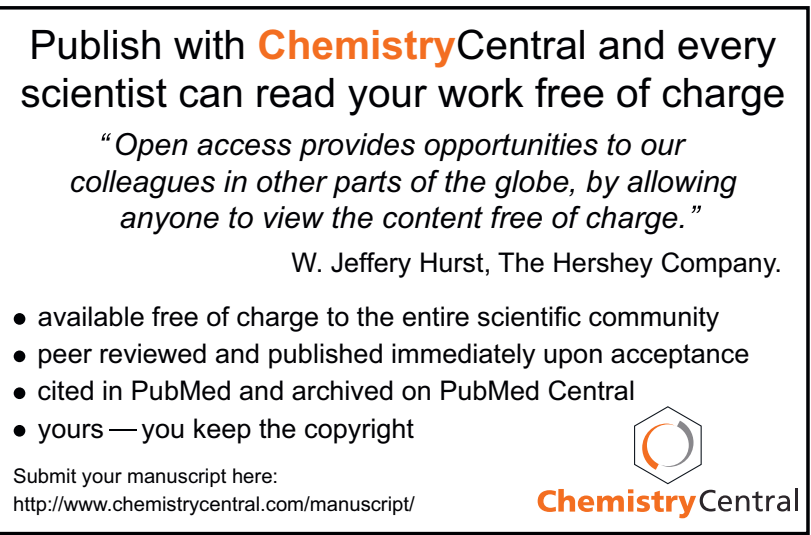

